\title{
Improving Classroom Instructions: Through Effective Classroom Management Approach in Nigeria Basic Education System
}

\author{
El-Yakub Bala \\ Department of Educational Foundations and Management, \\ Federal College of Education (Technical), Bichi \\ P.M.B 3473 Kano, Nigeria
}

\section{Doi:10.5901/jesr.2013.v3n5p37}

\begin{abstract}
This paper focused on improving classroom instruction through learner centered classroom management approach at the basic level of education in Nigeria. The paper highlighted different strategies of learner centered classroom management which will enhance effective instructions in classes at the grassroots level of education system of the country. Among the strategies discussed are; organizing classroom and supplies, establishing classroom norms and expectations, pestering pupils accountability planning and conducting instructions, communicating skills for teachers, managing problem behavior, maintaining appropriate pupils' behavior. Also conclusion and recommendations were drawn from the discussion of this text. Among the recommendations drawn were; seminars, workshops and conferences should be organized for the teachers of basic education on classroom management, the participants should step dawn the skills they acquired to the teachers in their duty post, remuneration should be adequately provided so it will motivate the teachers to teach effectively and government should supply adequately the needed teaching facilities so the teachers will teach effectively and efficiently, among others.
\end{abstract}

Keywords: Improvement, Learner-Centered, Classroom Management, Effectiveness Instructions

\section{Introduction}

Classroom management is one of the critical ingredients of effective instructions, so effective teaching/learning cannot take place in poorly managed classroom. Effective teachers appear to be effective with pupils of all achievement levels, regardless of the levels of heterogeneity in their classes. Marzano, (2001) in (Davis,2012) indicates that pupils in classes of teachers are classified as most effective by gaining fifty and above percentages point in their achievement over a lesson. This can be achieved by an important role played by teacher as classroom managers.

In the context of this paper classroom management is viewed in line with learner - centered approach following Pollack (2011) as "one that runs smoothly, with minimal disturbance in the learning environment of a group of individuals within a classroom setting. Classroom management and instruction are not separate, but are interwoven and complex. The interwoven nature of classroom management and classroom instruction is especially easy to see from pupil's perspective". Bala (2010) further confirmed that "pupils have at least two cognitive demands on them at all times: academic task demand (understanding and working with content) and social task demand (interacting with others concerning that content". The teacher must facilitate the learning of these academic and social tasks, for the understanding of the learning content and finding 
appropriate and effective ways to participate in order to demonstrate that understanding by organizing his instruction through:-

$\checkmark$ Teacher balances lessons with teacher - talk and learner talk as appropriate, but with the balance tending toward learner participation.

$\checkmark$ Learners given activities that will encourage them to become critical thinkers and problem solvers.

$\checkmark$ Learners learn by doing things, working collaboratively in teams/groups or pairs.

$\checkmark$ Learners develop the ability to integrate new knowledge into what they already know.

$\checkmark$ Learners given ample activities to encourage them search for and share information, investigate and report on topic; to discover for themselves.

According to Vivian (2010), instruction can be seen as "purposeful direction of learning process and is one of the major teacher class activities along with planning and management." Classroom in the word of Bala (2010) can be seen as "a room in which teaching or learning activities can take place and it can be found in educational institutions". Based on the definitions of instruction and classroom, we can see that classroom instruction in learner - centered class in the opinion of Garba (2012) means a purposeful direction of learning process along with planning and management in an organized classroom for the vivid understanding of concepts and interactions.

Based on the text and content above, this paper intents to explore strategies that will facilitate improvement in the quality of classroom instructions.

\section{Organizing Classroom and Supplies}

Arranging the physical setting for teaching is a logical starting point for classroom management because it is a task that the teacher faces before school begins. Many teachers found it easier to plan other aspects of classroom management once they know how physical features of the classroom will be organized. Four keys to good room arrangement according to Worseham (2006) are "keep high - traffic areas free of congestion, be sure pupils can see teachers easily, keep frequently used teaching materials and pupils supplies readily accessible and be certain pupils can easily see the presentation and pupils desk arrangement in small group or fairs.

\section{Establishing Classroom Norms and Expectations}

For pupils to have a successful year in a classroom, they must understand and practice the behaviors a teacher expect of them because the teacher will want appropriate and cooperative behavior in the classroom. Vivian (2010) further stressed that "effective teachers generally involve pupils in the democratic process of determining classroom rules, but generally the rules entail respect and courtesy toward all pupils, be prompt and prepared, instead quietly while others are speaking, and obey all school rules.

\section{Fostering Pupils Accountability}

Additional procedures are needed to encourage pupils to complete assignments and to engage in other learning activities. Pollock (2011) stressed that "Ultimately, the goal of any accountability system is to help pupils develop into independent learners, thus teacher's procedures should give as much responsibility as possible to pupils themselves, rather than having the pupils depend on either teacher or their parents to see that assignment are completed. Pollock (2011) further stressed the following as important to pupils' accountability: "clear communication of assignment and work requirements, monitoring progress on and completion of assignments and feedback to pupils. 


\section{Planning and Conducting Instruction}

After classroom is organized, establishing norms and expectations, developing rules and procedures and a system in place to manage pupils learning. Now that teachers pupils are attentive and ready to participate comes the point that management and instruction meet.

Well - planned lesson with a variety of developmentally appropriate activities support the positives learning environment a teacher operated.

Vivian (2010) categorized planning instructional activities in to the fallowing types include both long - range and short - range. Accomplishing the longer plan requires dividing the work in to terms, the terms into units, and the units into weeks and days.

Types of instructional activities in the word of Vivian (2010) include "content development (whole group instruction), grouped basic skill instruction, individual work and feedback, more so planning for clear instruction according to Vivian (2010) include "presenting new concept, checking for understanding and re-teaching.

\section{Concepts of Managing Whole Group Instruction}

A central theme in managing teacher - led activities well is the idea of activity flow the degree to which a lesson proceeds smoothly without digressions, diversions of interruptions, lesson with the good flow keep pupils attention and prevent deviation between most of the cue for behaviors' during the lesson are focused on behavior appropriate for the lesson. Vivian (2010) enumerated the following as a concept of managing whole - group instruction:-

Preventing misbehavior:- wittiness is the degree to which the teacher corrects misbehavior before it intensifies or spreads to more pupils and also targets the correct pupils when doing so. Also overlapping refers to how the teacher handles two or more simultaneous events.

Managing movement: where as witness and over lapping are accomplished by handling external interruption and pupils intrusions into the flaw of the lesson, movement management is accomplished by avoiding teacher - caused intrusions or delays. Also momentum refers to spacing and is indicated by lessons that move along briskly. More so smoothness is epitomize in lesson continuity. A smooth flowing lesson keeps pupils attention.

Maintaining group focus: in trying to maintain group focus the teacher should note the following: a teacher must be conscious of the group influence on the instruction, group alerting this means taking action to engage the attention of the whole class while individuals are responding, accountability also occurs when the teacher let the pupils know that their performance will be observed and evaluate the same manner and high - participation format are lesson that program the behavior of pupils when they are not directly involved in answering a teachers questions.

Common problems in conducting instruction: this is happing when conducting instruction among which are: transitions is the interval between any two activities problems include long delay which can attribute to high levels of inappropriate or disruptive behavior, clarity involves stating goals or major objectives and making sure that pupils know what they are accountable for learning or doing, carefully outlining a lesson sequences moving from simpler to more complex ideas; providing instruction both orally and in writing: checking understanding by along specific questions or obtaining work samples; and providing for meaningful practices and feed back through class work or home work assignments that review all lesson skills and content.

\section{Monitoring Appropriates Pupils Behaviors}

Teacher in learner - centered approach to classroom management should engaged in following strategies, as opined by Bala (2010) that: monitor pupils behavior during whole group presentations, small group instruction, individual work, by moving around the room during cooperative group work, and monitor completion of assignments, also management of 
inappropriate behavior. Make eye contact or move closer to pupil's use a signal such as finger to the lips or a head shake, to prompt the inappropriate behavior monitor until the pupils complies.

Provide a simple reminder of the correct procedure by either starting the procedure of asking the pupils to recite the procedure redirect pupils to task if he is off - task. Ask the pupils to stop misbehavior.

\section{Communication Skills for Teaching}

The teachers should note the following when presentations in a class with the medium of teaching recommended by the society:- Bala (2010) further itemized the following when instructions in a class:-

Constructive assertiveness describe your concerns clearly, insist misbehavior be corrected, and resists being manipulated, empathic responding - listen to the pupils perspective and react in ways that maintain a positive relationship and encourage further discussion, problem solving includes several steeps for reaching mutually satisfactory solutions to problems, it requires working with pupils to develop the plan.

\section{Managing Problem Behaviours}

Teachers should maintain problem behavior in learner - centered classroom when instructions are taking place through the following management strategies according to Bala (2010):-

Minor intervention: this involve the use of nonverbal cues, get the activity going, use proximity, use group focus, redirect behavior, provide ruled instruction, issue a brief desist, give the pupils choices.

Moderate interventions: with hold a privilege or desired activated, isolate or remove pupils, use penalty, assign detention, use a school - based consequence.

More extensive interventions:- use problem solving, use fire - steps intervention procedure, use "thick time" strategy, use the reality therapy model, confer with parent, create an individual contact with the pupils.

Special problems: bullying, tattling, rudeness toward teacher, chronic avoidance of work, frightens, power strangle.

\section{Conclusion}

At the conclusion of this paper, the paper stress that, it is pertinent to teachers of basic education to focus their attention on the processes and procedures involved in the classroom management according to the learner - centered principles which has direct bearing in an effective instructions in the classroom. Classroom management as discussed in this text focuses on improving classroom teaching/learning, classroom approaches, methods, and techniques to promote teaching to monitor learner progress and the effective use of available resources. The paper also make teachers in basic education system to reflect on their current knowledge and practice of classroom management and to use this as base for integrating new concepts and approaches to move from the traditional teacher - centered to the continuum of learner - centered which demonstrate alternatives to the effective instructions in basic education classes.

\section{Recommendations}

Arising from the discussing of this paper it is hereby recommended that:-

$\checkmark$ There is an urgent need to recruit more trained teachers to cope with the strength of an ever increasing number of basic schools in the country most importantly know that the programmed is in full swim. 
Classroom management content in teacher education training should be given much more priority and carry out with the sole aim of improving the standard of teaching in our classes.

$\checkmark$ The workshops that are organized by the federal government and state annually to refresher the teaching methodology of teachers at the grassroots' level; classroom management should accord a top priority with the sole aim of improving the effectiveness. The facilitators should be objective and constructive when given the training to the participants. And the participant should steep - down what they learn to the other teachers in their duty post.

The head teachers should take up the supervisory role in their school setting so as to ensure improvement in quality instructions in the basic classes.

Government as a matter of urgency should ensure adequate provision of the needed teaching facilities this will serve as motivation to effective instructions in the classroom at the basic level.

Adequate renumuration should be provided to the teachers as this will energize the teachers to teach effectively in the school.

Seminars conference and workshops should be organized on classroom management and teachers at the basic level of education should be encouraged to attend.

\section{References}

Bala E. (2010). The Role of Local School Supervisors in Kano State Primary Schools.

Bichi J ournal of Education No.2 Volume 2.

Davis I.W (2012). Classroom Management for Elementary Teachers, Seventh Edition

Person Education: Basten.

Garba S.A. (2011). Supervision of Instructions New York Haper and Raw.

Pollock J.K (2011), Making Effective Use of Classroom Management Techniques.

I badan University Press I badan Nigeria.

SESP (2008). Leaner - Centred Approaches Core Module, Component I. Participant

Handbook. Teacher Professional Development Training Materials. Ministry of Education Kano State.

SESP (2008). Learning Management: Core Module, Component Participant

Handbook. Teacher Professional Development Training Materials. Ministry of Education Kano State.

Vivian G.K (2010) Modifying Whole - Class Instruction - Interactive Sarawiya Press Kano Nigeria. 
